\title{
A Seasonally Forced Ocean-Atmosphere Model for Paleoclimate Studies
}

\author{
ANDREAS SCHMITTNER \\ School of Earth and Ocean Sciences, University of Victoria, Victoria, British Columbia, Canada \\ THOMAS F. STOCKeR \\ Climate and Environmental Physics, Physics Institute, University of Bern, Bern, Switzerland
}

(Manuscript received 21 December 1999, in final form 12 June 2000)

\begin{abstract}
Seasonal forcing is applied to an idealized model of the ocean-atmosphere system by prescribing monthly values of solar insolation at the top of the atmosphere and wind stress at the ocean surface. In addition, meridional near-surface wind velocities are applied for the advection term in the parameterization of the atmospheric moisture transport. The simulated seasonal cycle is compared with observations and reanalysis climatologies. It is found that the model can reasonably well simulate the present-day seasonal cycle. Largest model errors are found in the performance of the hydrological cycle. The sensitivity of the thermohaline circulation is examined with respect to seasonal versus annual-mean forcing. It is shown that meridional overturning is increased (20\%) if seasonal forcing is applied instead of annual-mean forcing. Both seasonality in wind stress and insolation forcing contribute to the increased overturning. Two stable equilibria, one with deep water formation in the North Atlantic and one without, exist irrespective of seasonal or annual-mean forcing. However, lower sensitivity of the thermohaline circulation to meltwater input into the North Atlantic results if seasonal forcing is applied. It is shown that a large part of this difference is due to an increased effective vertical heat diffusion in the seasonally forced model. Vertical mixing is enhanced by the wind-induced seasonality in meridional overturning. A quantitative estimate of the difference in effective vertical eddy diffusivities between the seasonally and the annually forced model versions is given.
\end{abstract}

\section{Introduction}

There is substantial geological evidence that during the Quaternary (about the last 2 million years), the climate system has undergone large changes. Several ice ages with low temperatures, large continental ice sheets, and low sea level alternated with interglacials during which the global ice volume was substantially smaller and climate was warmer (Imbrie et al. 1992). It has been hypothesized that the glacial interglacial cycles are forced by astronomical variations in the earth's orbital parameters. These variations could change the solar insolation received by the earth's surface and triggering the buildup or melt of the large continental ice sheets (see Berger 1988 for a review).

Overlayed but somehow connected to these changes on long timescales $(\sim 100 \mathrm{ky})$ are rapid climate fluctuations recorded in Greenland ice cores (Dansgaard et al. 1993) during the last glacial. Although effort has

Corresponding author address: Dr. Andreas Schmittner, School of Earth and Ocean Sciences, University of Victoria, P.O. Box 3055, Stn CSC, Victoria, BC V8W 3P6, Canada.

E-mail: andreas@ocean.seos.uvic.ca been made in recent years to model the large-scale features of the glacial interglacial variations using simplified models (Berger et al. 1998; Paillard and Labeyrie 1994), the role of the oceans remains largely unexplored. After the continental ice sheets the oceans have the longest timescale $O(1000 \mathrm{yr})$ of variability in the climate system. About one-half of the equator-to-pole heat transport is made by the oceans. It has been suggested that at least some of the rapid changes during the last ice age have been induced by fluctuations of the thermohaline circulation in the North Atlantic (Bond et al. 1993; Broecker 1997).

In this study we supplement a climate model that includes the deep ocean circulation with the seasonal cycle. Since the changes in insolation from the astronomical (or Milankovic) theory are very small in the annual mean and much stronger if particular seasons are considered, a model suitable for a test of the Milankovic theory must resolve the seasons. The purpose of the present paper is to approach this problem for a loworder climate model whose atmospheric component consists of an energy balance model. We present the model spinup, coupling procedure and the performance of the present-day seasonal cycle.

The paper is organized as follows. Sections 2 and 3 
describe the model and the coupling strategy. In section 4 the present-day climate as simulated by the model is compared with various observational data and data from reanalyses. As a first application of the model we study the different steady states of the North Atlantic thermohaline circulation and the sensitivity for a transition between them concerning annual versus seasonal forcing in section 5 .

\section{Model description}

We use the zonally averaged ocean model of Wright and Stocker (1992), which consists of three basins representing the Pacific, the Atlantic, and the Indic connected through a zonally well-mixed Southern Ocean. A uniform depth of $4 \mathrm{~km}$ is assumed. The ocean is coupled to a vertically and zonally averaged energy balance model of the atmosphere (Stocker et al. 1992) supplemented with an active hydrological cycle (Schmittner and Stocker 1999). In the parameterization of the meridional moisture flux a slight formal change from Schmittner and Stocker (1999) is made. We write the meridional water vapor (or latent heat) flux $L$ according to Schmittner et al. (2000) as

$$
L=\alpha_{q} v q-K_{q} \frac{\partial q}{\partial y}
$$

where $\alpha_{q}=0.6$ is a constant of proportionality, relating the near-surface moisture flux to its vertically averaged value. The $v$ is a near-surface meridional wind velocity and $q$ is the specific humidity. A constant relative humidity $r=0.85$ is assumed, and the saturation specific humidity $q_{s}$ allows one to express $q=r q_{s}(T)$ in terms of near-surface air temperature $T$. The first term on the rhs of Eq. (1) represents the flux by the mean meridional circulation and the second term stands for the transport by transient eddies. For $v$ a monthly climatology of 10-m meridional wind velocities is used computed from the 15-yr (1979-94) reanalysis from the European Centre for Medium-range Weather Forecasts (ECMWF; Gibson et al. 1996).

Parameters and geometry are as described in Stocker and Wright (1996) if not mentioned otherwise. Up to now the model has been used in annual-mean mode only. The coupling procedure makes use of the steadystate heat and freshwater fluxes from the ocean spinup that leads to a stable state after coupling without the use of explicit flux corrections (Sausen et al. 1988). Therefore, uncertain atmospheric parameters, like for example emissivities or eddy diffusivities, are calculated using observations together with the fluxes from the ocean spinup. Each different ocean spinup therefore leads to different atmospheric parameters. This results in an atmospheric model component whose parameters are objectively tuned such that implied fluxes match those of the ocean perfectly. We apply "objective tuning" also for the seasonal forcing.

Stocker et al. (1992) have shown that the coupling method does not necessarily lead to a stable steady state after coupling. Transitions are possible if the ocean state prior to coupling is not sufficiently close to steady state, for example, if intermittent convection is present. Therefore it is not clear a priori that this method can be applied also for seasonal forcing. Here we will show that this is possible with slight changes of the coupling method described in Stocker et al. (1992). A perfect match could, of course, be achieved by varying all parameters with the month of year. But such an approach would lead to a highly parameterized and constrained model that is matched to the present-day climate. Thus, our philosophy is to use rather time-independent parameters and annual-mean quantities for their determination. In this case an independent validation of the parameterizations is possible for the present-day seasonal cycle.

\section{Spinup and coupling procedure}

The ocean is spun up by relaxing the sea surface temperatures (SSTs) and salinities to monthly mean observations at 30-m depth (Levitus et al. 1994; Levitus and Boyer 1994). Salinities in the northernmost box of the North Atlantic have been increased by 0.3 per mill in order to get a realistic salinity of the North Atlantic Deep Water (NADW). A monthly climatology of the zonal wind stress is computed from the ECMWF reanalysis and used as the upper boundary condition for momentum. After the model has reached a quasi-steady state, which occurs usually after 1000-3000 years, the atmosphere is coupled to the ocean. Note that the same wind stress will be applied after coupling since the energy balance model does not predict wind velocities. Heat and freshwater fluxes, however, can freely vary between ocean and atmosphere after coupling.

The determination of the atmospheric parameters closely follows Stocker et al. (1992). Note that heat and freshwater fluxes of the ocean spinup are used in order to avoid drift after coupling. It is important to stress that only annual-mean values are used for these calculations. At the top of the atmosphere (TOA) we use outgoing longwave radiation $Q^{\text {long }}$ and incoming shortwave radiation $Q^{\text {short }}$ data in $\mathrm{W} \mathrm{m}^{-2}$ from the Earth $\mathrm{Ra}$ diation Budget Experiment (ERBE 1990) modified by Trenberth (1997). For the outgoing longwave radiation $Q^{\text {long }}$ at the TOA a linearized version of the StefanBoltzmann law is used:

$$
Q^{\text {long }}=a+b T \text {, }
$$

where $a$ and $b$ are constants. Following North et al. (1983) we use $b=2 \mathrm{~W} \mathrm{~m}^{-2} \mathrm{~K}^{-1}$. The latitude-dependent constant $a(\phi)$ is calculated from Eq. (2) and annualmean values of zonally averaged near-surface air temperatures $T$ from the ECMWF re-analysis (ERA; Gibson et al. 1997).

The planetary albedo $\alpha(\phi)$ is determined according to 


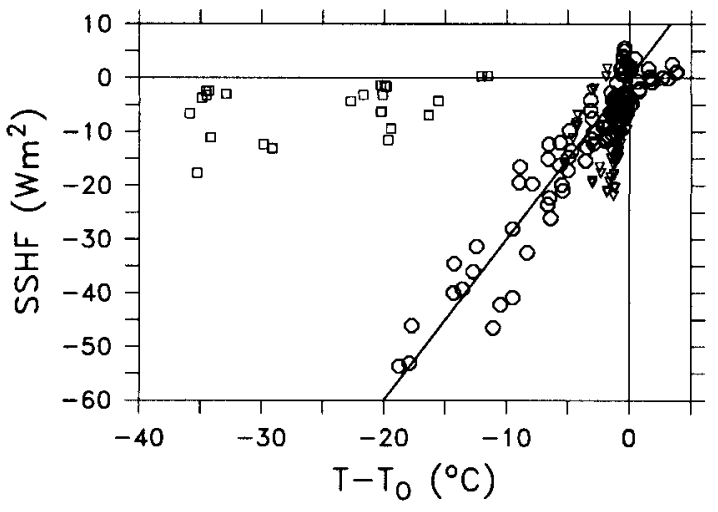

FIG. 1. Surface sensible heat flux (SSHF) vs the difference between sea surface temperature $T_{o}$ and air temperature at $2 \mathrm{~m}$. Monthly mean climatological data from the ECMWF reanalysis mapped on the model grid are used. Note that for air temperatures zonal means over ocean and land have been used. Latitudes between $20^{\circ} \mathrm{S}$ and $90^{\circ} \mathrm{N}$ are plotted as circles. Triangles represent latitudes between $20^{\circ}$ and $70^{\circ} \mathrm{S}$. The large fluxes despite small temperature differences are due to high wind speeds in the vicinity of the ACC. Squares denote latitudes over the Antarctic marginal seas south of $70^{\circ} \mathrm{S}$, where sea ice is present most of the year. Here a large fraction of the sea surface area is efficiently isolated from the atmosphere, which leads to small fluxes despite large temperature differences. A line with the slope of $3 \mathrm{~W} \mathrm{~m}^{-2} \mathrm{~K}^{-1}$ is added. Note that the fluxes are computed from the forecast model and that in the Southern Hemisphere they are more uncertain than in the Northern Hemisphere because of sparser observations there.

$$
\alpha=1-\frac{Q^{\text {short }}}{Q^{\text {solar }}},
$$

where $Q^{\text {solar }}$ is the solar insolation at the TOA calculated from Berger et al. (1993). In the model simulations discussed below $\alpha$ is held constant; that is, no temperature feedback on the albedo is allowed.

Then the atmospheric eddy diffusivity for sensible heat and potential energy $K_{T}$ is computed according to

$$
K_{T}=-F^{\text {merid }}\left(\frac{\partial T}{\partial y}\right)^{-1},
$$

where the annual-mean meridional heat flux $F^{\text {merid }}$ is calculated by integration of the vertical fluxes at the TOA and the heat flux at the ocean's surface from the spinup of the ocean model as described in Stocker et al. (1992).

The bulk coefficient for evaporation $c_{E}$ is calculated as by Stocker et al. (1992), with the difference that the above-mentioned near-surface air temperature data are used. Precipitation $P$ can then be diagnosed from the annual-mean freshwater flux at the ocean's surface as determined from the ocean spinup and from evaporation, $E^{\text {obs }}$, data from Baumgartner and Reichel (1975). The coefficients for the zonal distribution of precipitation are determined as described in Schmittner and Stocker (1999). Emissivities for downwelling longwave radiation are estimated following Stocker et al. (1992). They are forced to lay in the interval $[0,1]$. For the
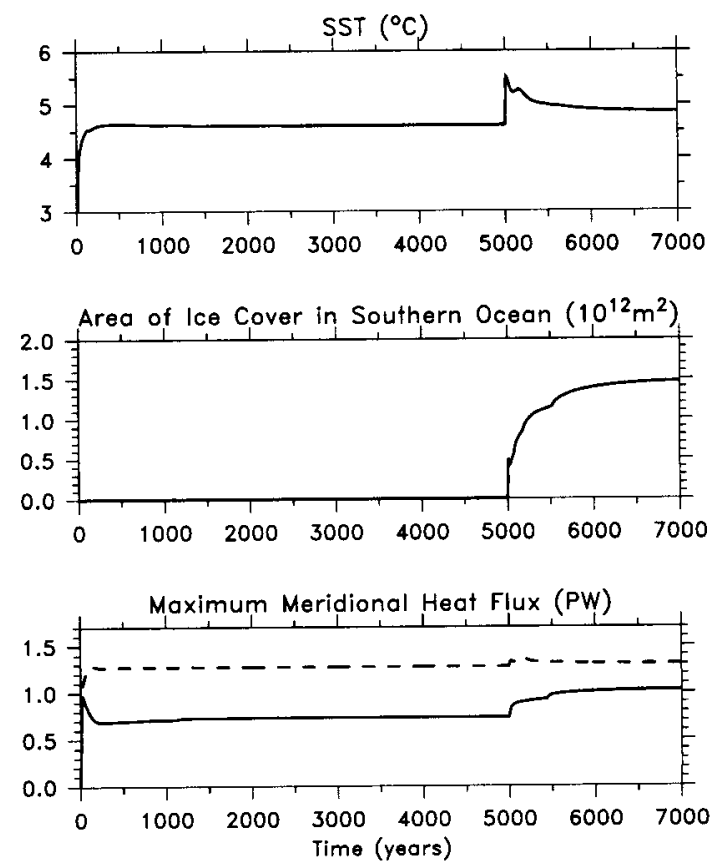

FIG. 2. Annual-mean time series of sea surface temperature in the northernmost box of the North Atlantic (top), area of ice cover in the Southern Ocean (middle), and maximum meridional heat fluxes (bottom) of the Pacific (solid) and Atlantic (dashed) from the spinup. The atmosphere model is coupled to the ocean at time $=5000 \mathrm{yr}$. After coupling the model shows a small drift due to beginning ice formation in the Southern Ocean.

transfer coefficient for sensible heat $D$ we use $D=3$ $\mathrm{W} \mathrm{m} \mathrm{m}^{-2} \mathrm{~K}^{-1}$ instead of $D=10 \mathrm{~W} \mathrm{~m}^{-2} \mathrm{~K}^{-1}$, which was the value used by Stocker et al. (1992). The reason is that we use near-surface air temperatures that are zonally averaged over ocean and land, while Stocker et al. (1992) used near-surface air temperatures averaged over the ocean only. In Fig. 1 the relation between the sensible heat flux and the air-sea temperature difference is shown as derived from the ERA climatology.

Eddy diffusivities for the meridional moisture transport are calculated by solving Eq. (1) for $K_{q}$ and using annual-mean 10-m wind velocities $v$ from the ECMWF reanalysis. The annual-mean latent heat flux $L$ is diagnosed from the ocean spinup by integrating the surface freshwater balance (Schmittner and Stocker 1999), and annual-mean near-surface air temperatures are again used from the ECMWF reanalysis in order to calculate $q$. Eddy diffusivities are also forced to be positive.

In Fig. 2 time series of the spinup from the seasonally forced model are shown. After coupling the model drifts into a new equilibrium. Sea surface temperature in the northern North Atlantic raises by $0.25^{\circ} \mathrm{C}$. In the North Pacific convection deepens, formation of North Pacific Intermediate Water increases and the maximum Pacific meridional heat flux increases consequently. The reason for the drift is difficult to assess. One point is that sea ice in the model is only allowed to form after coupling. Increased sea ice cover isolates the ocean from the at- 

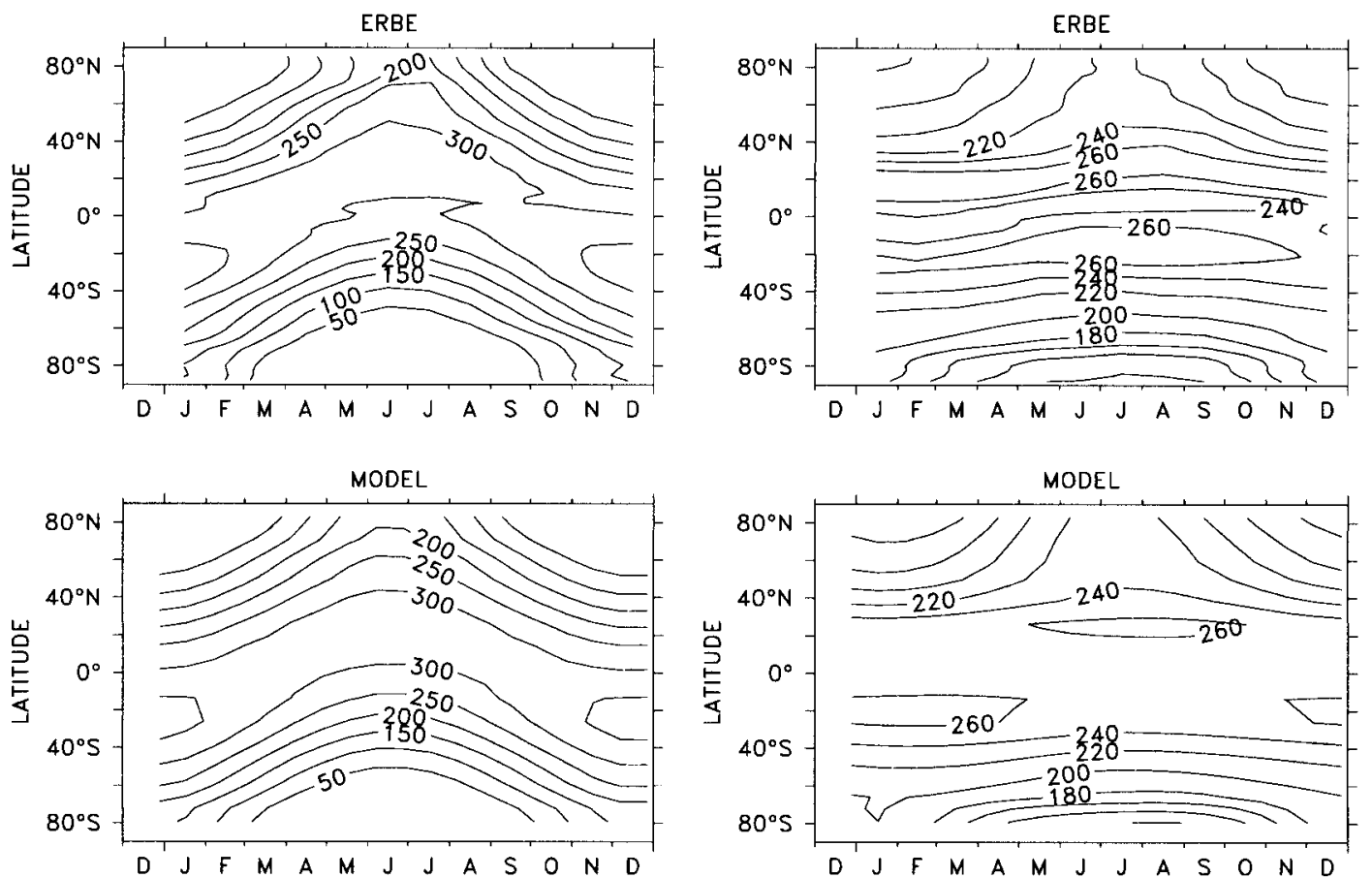

FIG. 3. Zonally averaged vertical heat fluxes at the top of the atmosphere $\left(\mathrm{W} \mathrm{m}^{-2}\right)$ as a function of latitude and month of year. Net incoming solar radiation (left panel) is contoured with isoline differences of $50 \mathrm{~W} \mathrm{~m}^{-2}$ and longwave radiation into space is contoured with isoline differences of $20 \mathrm{~W} \mathrm{~m}^{-2}$. Adjusted satellite observations from ERBE (Trenberth 1997) are shown in the upper panels averaged to a mean seasonal cycle. In the lower panels the model results are shown.

mosphere and inhibits vertical heat fluxes. Another reason is that at some locations negative values of $K_{q}$ or emissivities larger than one are diagnosed at the time of coupling. These unrealistic values are adjusted, which leads to slightly different heat and freshwater fluxes before and after coupling. Another point is that the strong restoring boundary conditions during the ocean spinup lead to strong seasonal variations of the surface fluxes that are unrealistic. Thus the seasonal variations of the surface fluxes will change after coupling and this may also lead to a certain drift. Nevertheless, the new equilibrium is very close to the state prior to coupling.

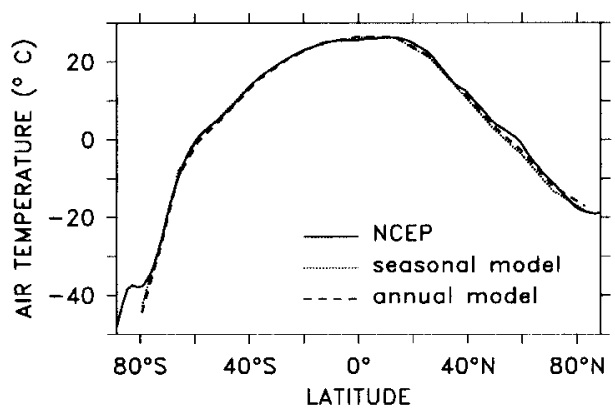

FIG. 4. Annual-mean, zonally averaged, near-surface air temperatures as a function of latitude. Results from a seasonally forced model version (dotted) and a version with annual-mean forcing (dashed) are compared with data from the NCEP reanalysis (solid).

\section{Performance of the present-day seasonal cycle}

Two model versions have been run: one in which the full seasonal forcing as described in the last section is applied, and a second version where exactly the same model parameters are used but the forcing is done with annual-mean values of insolation, wind stress, and meridional wind velocity. First we discuss the performance of the atmosphere model component in section $4 \mathrm{a}$, where we compare the modeled variables with reanalysis data from the National Centers of Environmental Prediction (NCEP) (Kalnay et al. 1996) and with satellite measurements at the TOA. Then in section $4 \mathrm{~b}$ results from the ocean model are compared with observations.

\section{a. Atmospheric variables}

Beginning at the TOA, in Fig. 3 modeled net shortwave and thermal radiative fluxes are shown together with the observations. Both long and shortwave fluxes are well represented in the model. Largest differences between model results and observations are smaller than $15 \%$ and occur in the Tropics for the outgoing longwave radiation.

In Fig. 4 annual-mean air temperatures are presented from the two model versions and from the NCEP reanalysis. Both the seasonally forced version as well as the version with annual-mean forcing reproduce the re- 

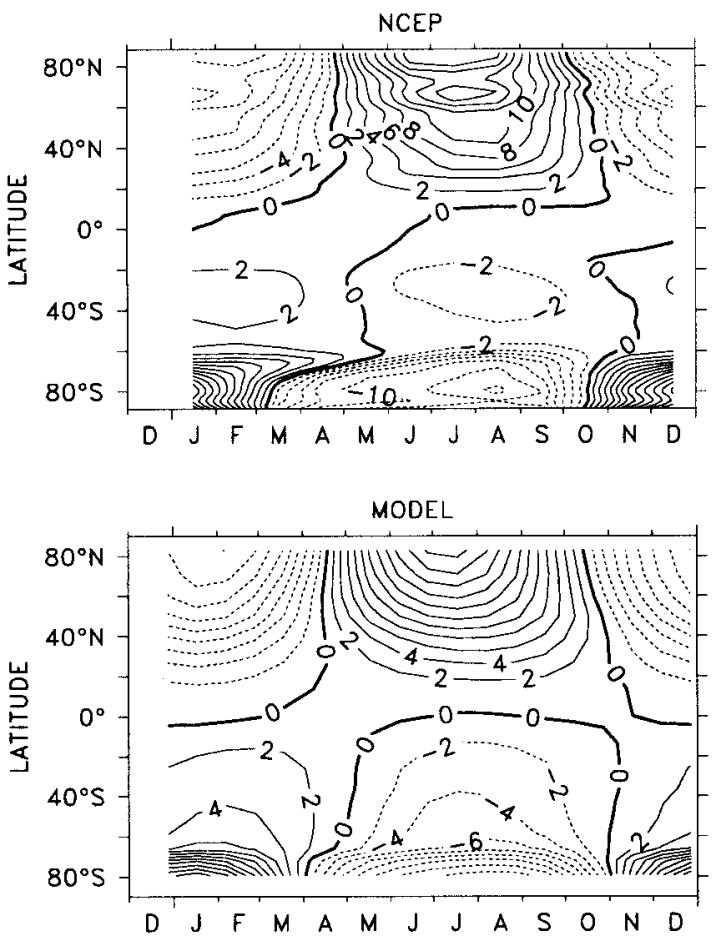

FIG. 5. Zonally averaged near-surface air temperature anomalies as a function of latitude and month of year. Results from the model (lower panel) are compared with data from the NCEP reanalysis (upper panel).

analysis results very well. This is not surprising since annual-mean near-surface air temperatures have been used to determine atmospheric model parameters. It should be noted that for the parameter determination ECMWF temperatures have been used. But these compare very well with the NCEP reanalysis.

How well can the model simulate the seasonal cycle of the low-level air temperature? In Fig. 5 the anomalies of near-surface air temperature are shown for the model together with the NCEP reanalysis data. Both the amplitude as well as the phase of the zonally averaged seasonal temperature variations are quite well repro- duced by the model. The model slightly overestimates the amplitude and at high southern latitudes the phase is delayed by less than one month. Although the model parameters were determined with annual-mean information only, the model can surprisingly well simulate the seasonal cycle of the surface air temperatures.

Annual-mean results of zonally averaged precipitation are shown in Fig. 6. The general shape of the reanalysis with maxima of rainfall in the Tropics and at midlatitudes and minima in the subtropics is well reproduced by the model. However, the amplitudes in the extratropics seem to be too large by up to a factor of 2. Note that the smaller-scale features present in the reanalysis data, for example the two maxima in the Tropics, cannot be resolved by the model due to its coarse resolution. Note also that no precipitation data have been used in the determination of the model parameters. The seasonal variations in precipitation are shown in Fig. 7. While the performance of the seasonality in rainfall is well reproduced at low latitudes, the variability is overestimated at mid- and high latitudes especially in the Northern Hemisphere.

Zonally averaged evaporation is shown in Fig. 6 as annual averages. High evaporation rates are found in the subtropics and minima occur in the Tropics and at high latitudes. The agreement with the reanalysis is better than for precipitation, which again is not surprising, since evaporation data have been used for the calculation of parameters. The seasonal performance (Fig. 7) is in poorer agreement with the reanalysis data than the annual mean. The variability is overestimated by the model particularly in mid- and high latitudes. At northern high latitudes in summer even the sign of the anomaly is wrong. This shows the limitation of the simple parameterization of evaporation (Stocker et al. 1992) that is only dependent on air temperature and SST. In reality evaporation strongly depends on the low-level wind velocity. Since the atmospheric model component contains no dynamics, it cannot simulate wind velocities, and therefore we must accept this limitation. The errors in the seasonal cycle of precipitation are largely
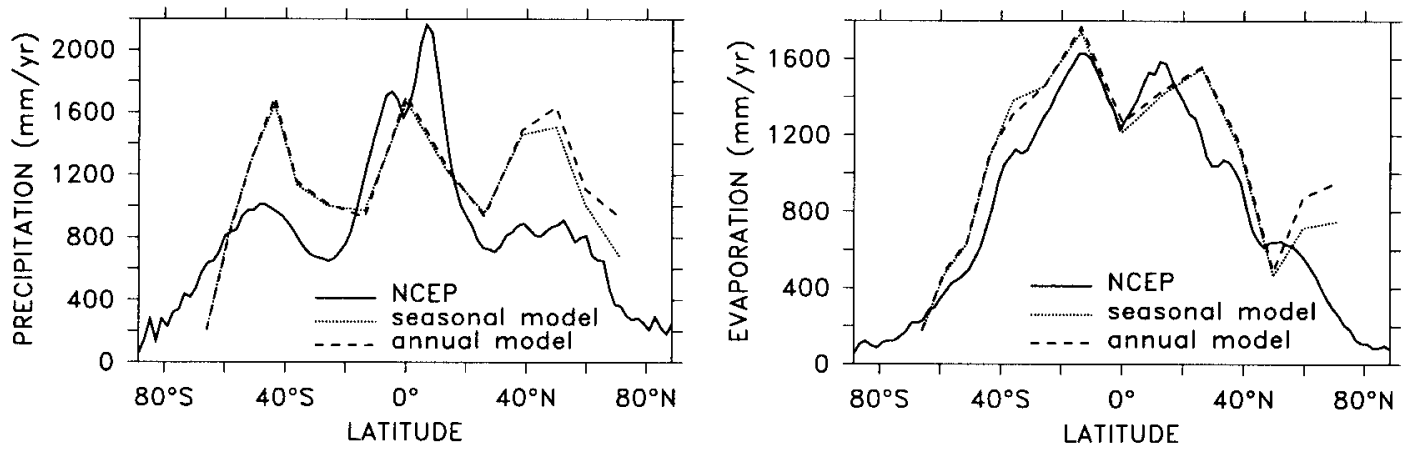

FIG. 6. Annual-mean zonally averaged (left) precipitation and (right) evaporation as a function of latitude. Results from a seasonally forced model version (dotted) and a version with annual-mean forcing (dashed) are compared with the NCEP reanalysis (solid). 

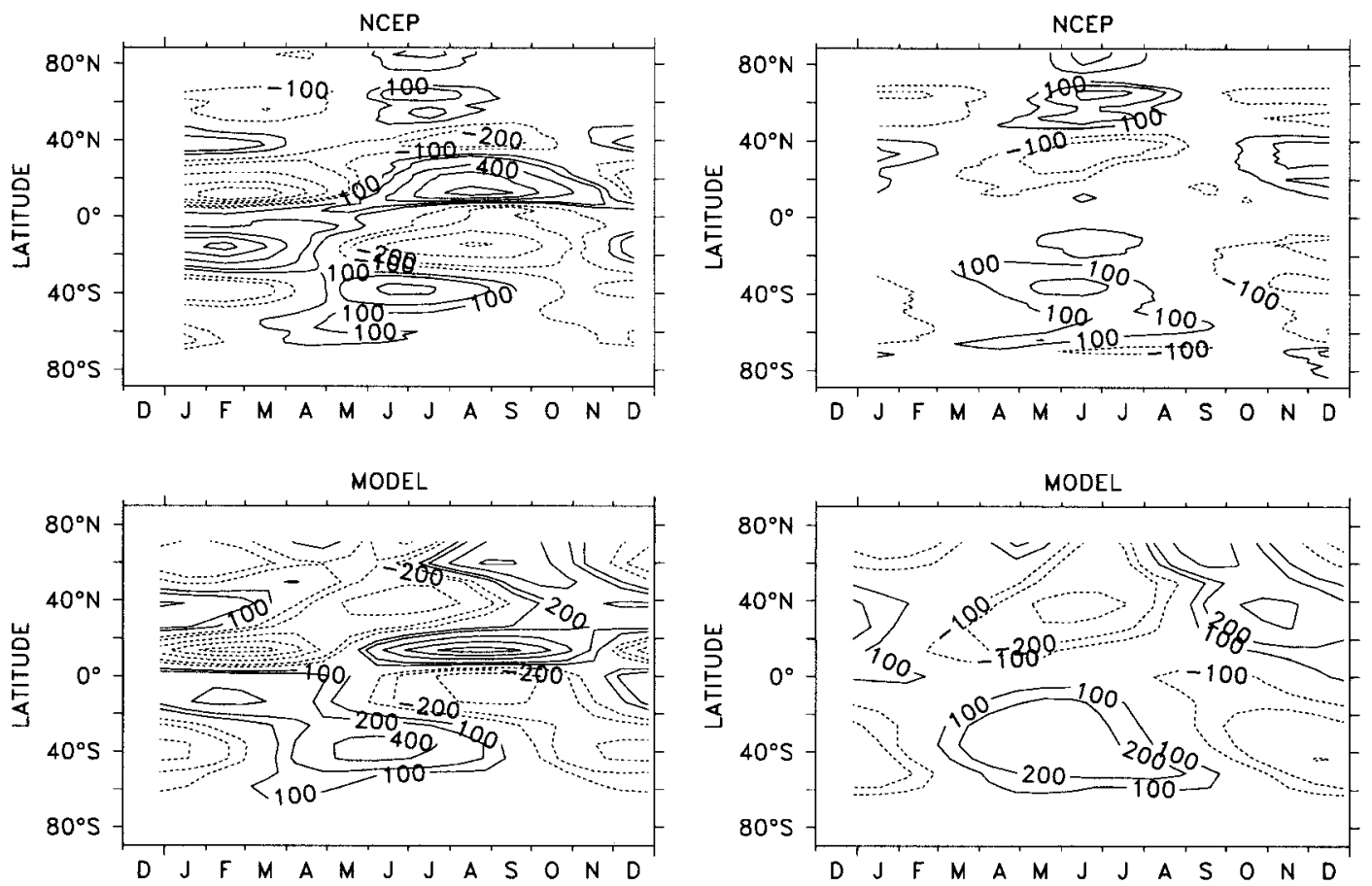

FIG. 7. Zonally averaged (left) precipitation and (right) evaporation anomalies $\left(\mathrm{mm} \mathrm{yr}^{-1}\right)$ as a function of latitude and month of year. Results from the model (lower panels) are compared with data from the NCEP reanalysis (upper panels). Contour intervals are $200 \mathrm{~mm} \mathrm{yr}^{-1}$ with additional isolines at $\pm 100 \mathrm{~mm} \mathrm{yr}^{-1}$.
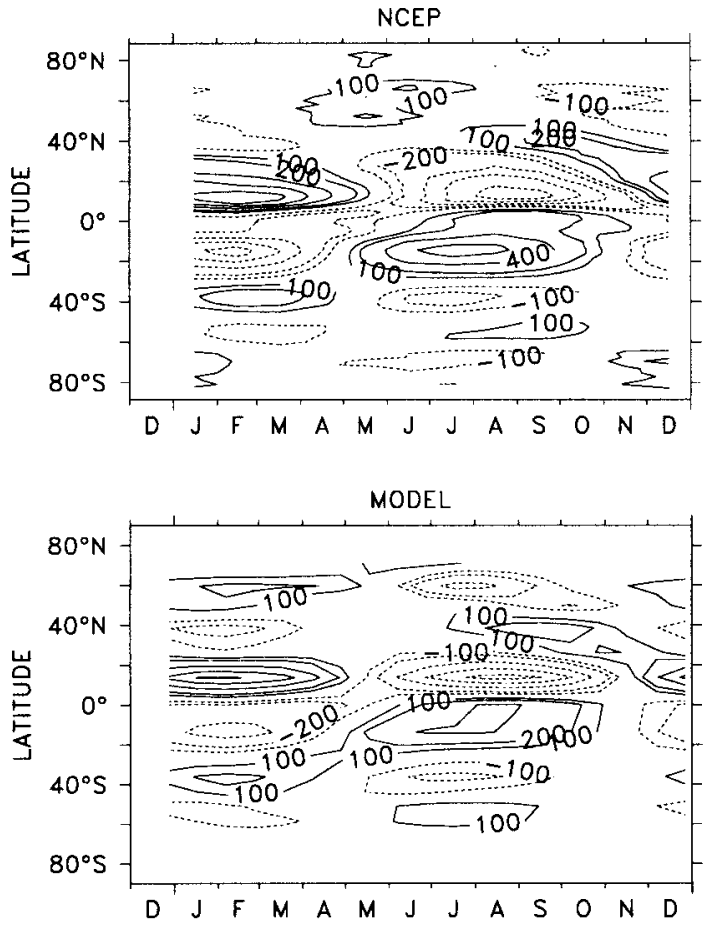

FIG. 8. Zonally averaged freshwater flux out of the ocean $(E-P)$ as anomalies from the annual mean $\left(\mathrm{mm} \mathrm{yr}^{-1}\right)$ as a function of latitude and month of year. Contours as in Fig. 7. influenced by the errors in evaporation. This is due to the fact that precipitation is calculated as a residual from the divergence of the latent heat flux and evaporation (Schmittner and Stocker 1999). The latent heat flux is in good agreement with the reanalysis data (see Fig. 9) and does not vary much poleward of $40^{\circ}$, hence precipitation must balance evaporation there. The freshwater flux out of the ocean $E-P$ as shown in Fig. 8 is less erroneous since the individual errors of evaporation and precipitation partly cancel each other. The errors in the simulated seasonal cycle of evaporation and precipitation will have an impact on SSTs and air temperatures. However, their influence on the simulated seasonal cycle in air temperatures (see Fig. 5) is not very large. We will show below that the same is true for the simulation of SST.

The modeled seasonal cycle of both latent and sensible meridional heat fluxes is in reasonable agreement with the reanalysis data (Fig. 9). The amplitude of the tropical changes in latent heat flux is underestimated by $30 \%$ but the phase is well reproduced by the model. The sensible heat flux variations are in even better agreement with the reanalysis. The modeled latent heat flux consists of an advective part, represented by the first term on the rhs of Eq. (1) and a diffusive part, represented by the second term on the rhs of Eq. (1). The advective part, which should mimic the effect of the mean meridional circulation, is strongest at low latitudes, while the diffusive part, which represents the 

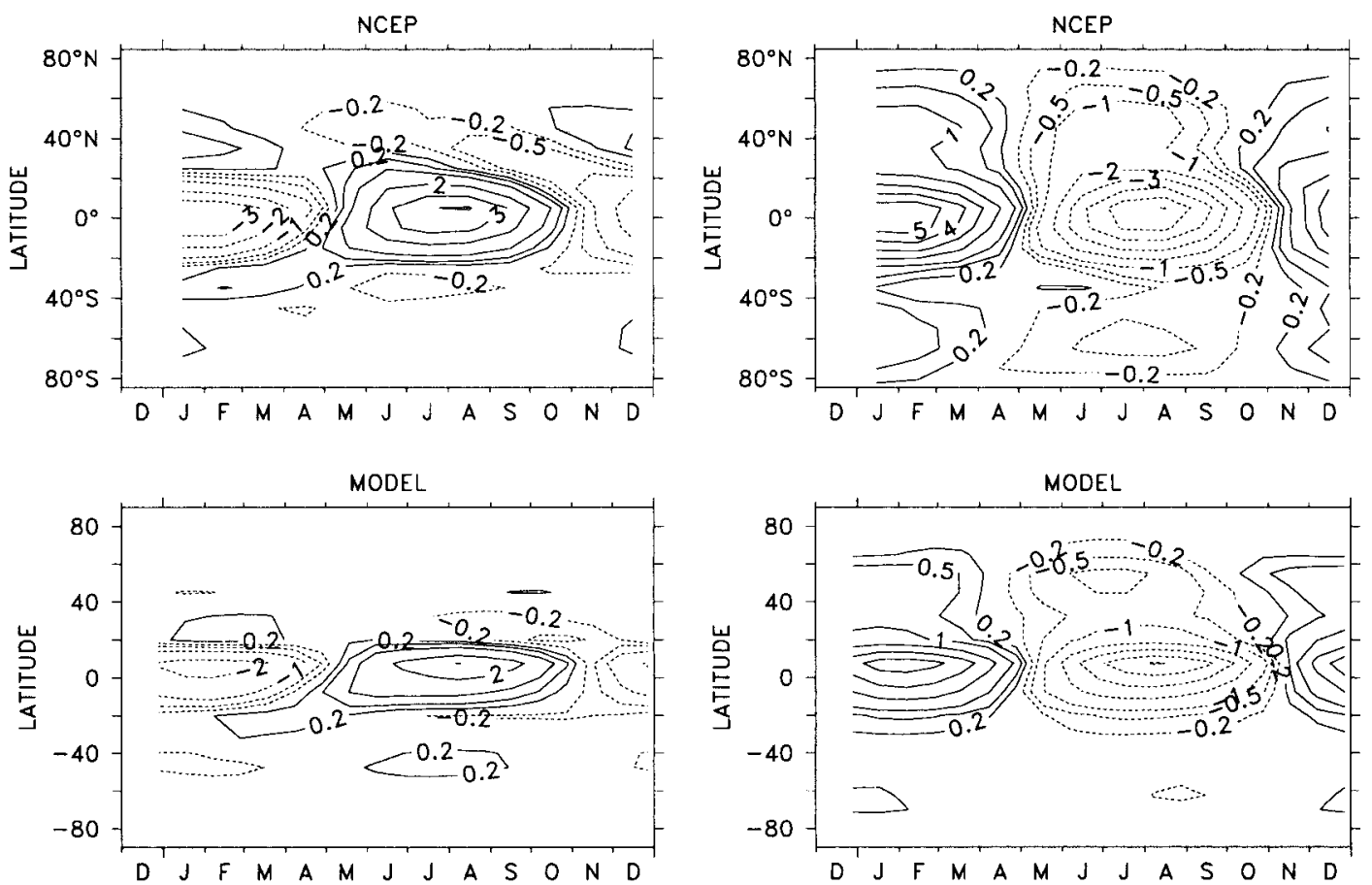

FIG. 9. Zonally averaged atmospheric meridional heat flux anomalies (PW; $1 \mathrm{PW}=10^{15} \mathrm{~W}$ ) as a function of latitude and month of year. Latent heat fluxes (left panels) and sensible heat fluxes (right panels) are contoured with isoline intervals of $1 \mathrm{PW}$ and additional contours at $\pm 0.5 \mathrm{PW}$ and $\pm 0.2 \mathrm{PW}$. Results from the model (lower panels) are compared with data from the NCEP reanalysis (upper panels).
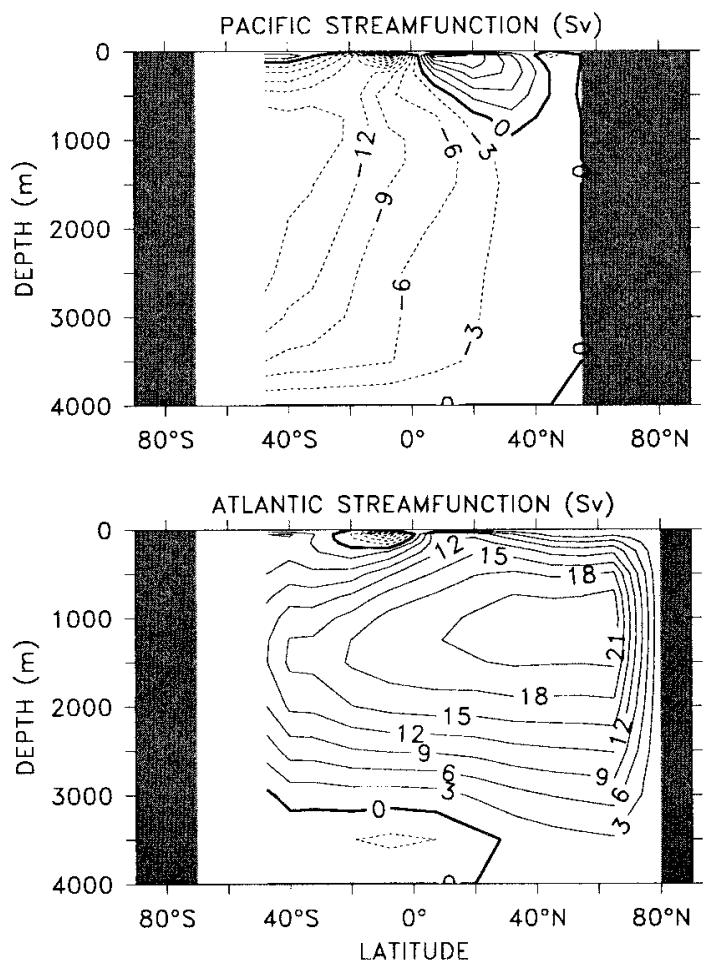

FIG. 10. Latitude-depth section of simulated annual-mean streamfunction of the Pacific (upper) and Atlantic (lower) oceans in Sverdrup $\left(1 \mathrm{~Sv}=10^{6} \mathrm{~m}^{3} \mathrm{~s}^{-1}\right)$. Isoline difference is $3 \mathrm{~Sv}$. transport by transient eddies, dominates at midlatitudes. This is also in qualitative agreement with observations (Peixoto and Oort 1992).

\section{b. Oceanic variables}

The annual-mean streamfunction of the Pacific and Atlantic Oceans simulated by the seasonally forced model is shown in Fig. 10. Deep water is formed in the northern North Atlantic and in the Southern Ocean. The NADW sinks to depths between 1.5 and $3.5 \mathrm{~km}$ then flows southward crossing the equator and finally entering the Antarctic Circumpolar Current (ACC). Then the deep water flows into the Pacific and Indic (not shown), where it slowly upwells. The return flow back to the North Atlantic occurs in surface and subsurface waters. Antarctic bottom water (AABW) flows northward in the Atlantic to about $20^{\circ} \mathrm{N}$. This simulated global ocean circulation is broadly consistent with the conveyor belt picture (Schmitz 1995).

Global overturning also exhibits a strong seasonal cycle. Figure 11 shows the difference of the global streamfunction between the winter and summer half of the year. Three wind-induced (Ekman) cells appear: a strong one at low latitudes and two weaker at mid- and high latitudes. This is in accordance with results from three-dimensional ocean models (Bryan and Lewis 1979; Nakano et al. 1999).

Modeled annual-mean distributions of temperature 


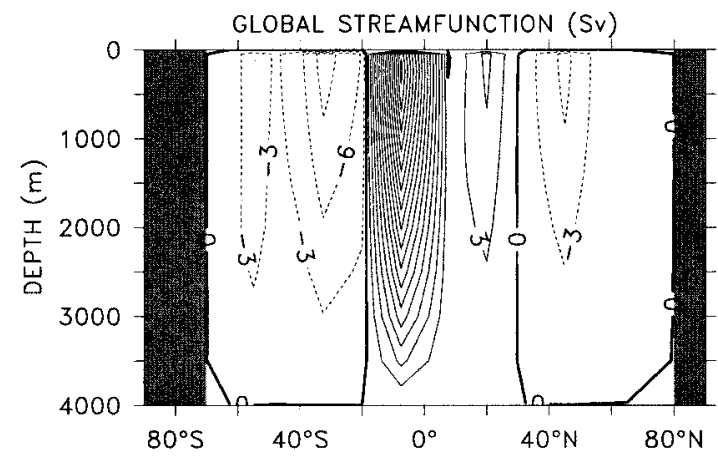

FIG. 11. Latitude-depth section of simulated seasonality of the global streamfunction. Winter (Nov-Apr) average minus summer (May-Oct) average is shown. Isolines as in Fig. 10. The maximum value of $49 \mathrm{~Sv}$ occurs at $250-\mathrm{m}$ depth at $7.5^{\circ} \mathrm{S}$.

and salinity are shown in Figs. 12 and 13 together with observations. Generally, the agreement between model and observations is good. The deep Pacific is colder than the deep Atlantic except for the south Atlantic that is filled with cold AABW. The modeled thermocline is slightly too diffuse, so that deep and intermediate waters get somewhat too warm. In the salinity distribution of the Atlantic the different water masses are well simulated except for the influence of the Mediterranean outflow that is not included in the model. NADW enters from the north with a salinity of about 34.9 per mill, while northward-flowing Antarctic intermediate waters at about $1000-\mathrm{m}$ depth and AABW are much fresher.
In the Pacific no deep water is formed, which results in a fresher deep ocean. Instead intermediate waters from northern and southern origin are present. The simulated intrusion of the Pacific intermediate waters is too deep compared with the observations (note the depth of the equatormost extension of the 34.55 isoline).

Basin-averaged depth profiles of temperature and salinity are plotted in Fig. 14 for both model versions. Generally, the agreement with the observations is quite good. Obvious differences between model results and observations are found in the Southern Ocean where deep waters are too warm and fresh in both model versions. The simulated thermocline in the Pacific is too deep. Slight improvements are seen for the seasonally forced version particularly in the deep Atlantic and shallow Pacific salinities.

Seasonal anomalies of SST from the model simulation are compared with observations in Fig. 15. The model performance is in excellent agreement with the observations. By comparison with Fig. 5 we note that SSTs lag the near-surface air temperature changes by one to two months. The annual cycle of the modeled zonally averaged vertical heat flux at the ocean surface shows maximum heat fluxes of more than $200 \mathrm{~W} \mathrm{~m}^{-2}$ at high northern latitudes in winter (not shown). Its simulated seasonal variability is consistent with three-dimensional model results (Maier-Reimer et al. 1993).

Figure 16 shows the development of the mixed layer in the northernmost North Atlantic model grid box. A shallow very stably stratified surface layer is present
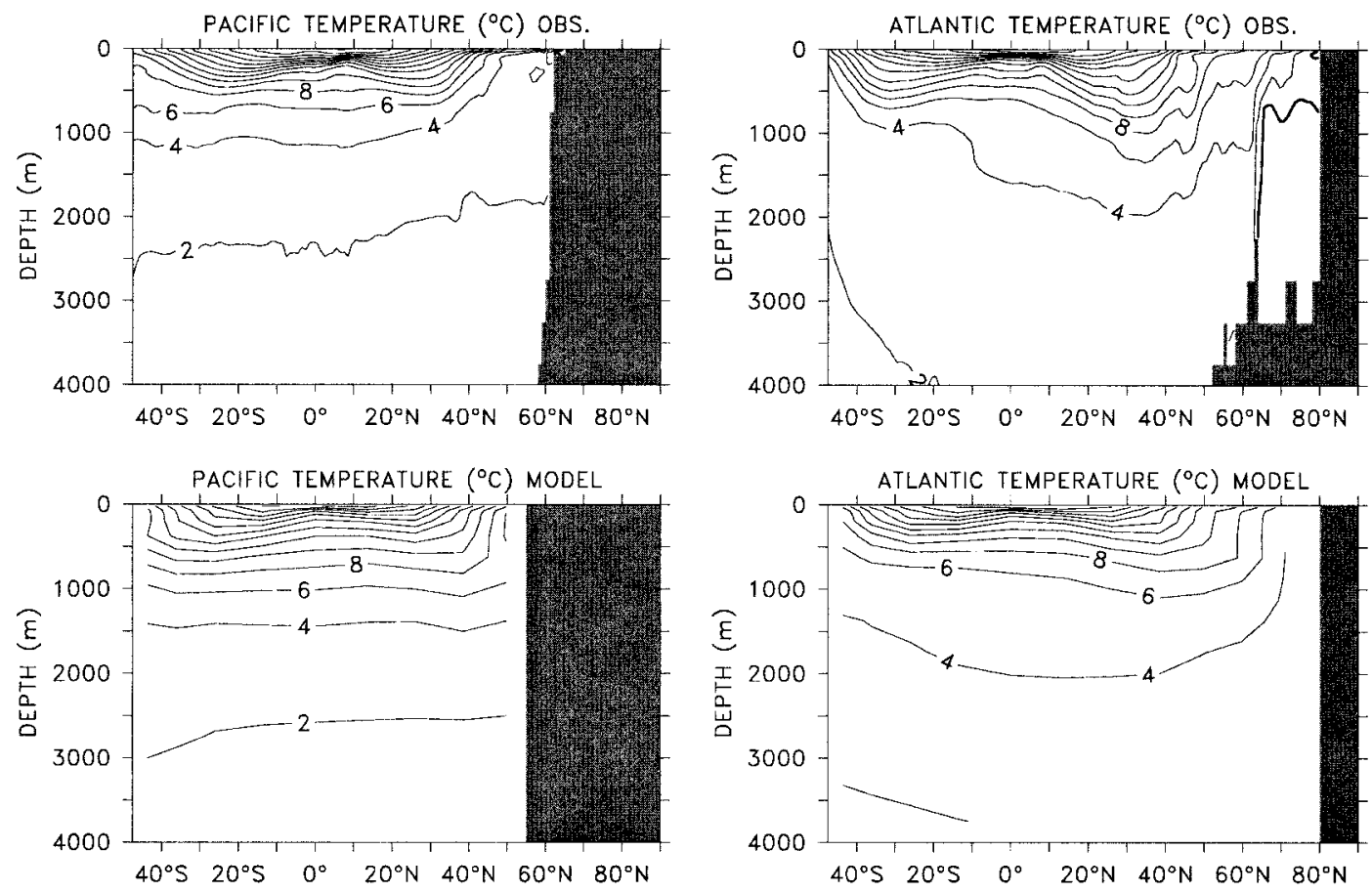

FIG. 12. Latitude-depth sections of simulated (lower panels) annual-mean temperatures in the Pacific (left) and Atlantic (right) Oceans. Upper panels show zonally averaged observations from Levitus and Boyer (1994). Isoline differences are $2^{\circ} \mathrm{C}$. 

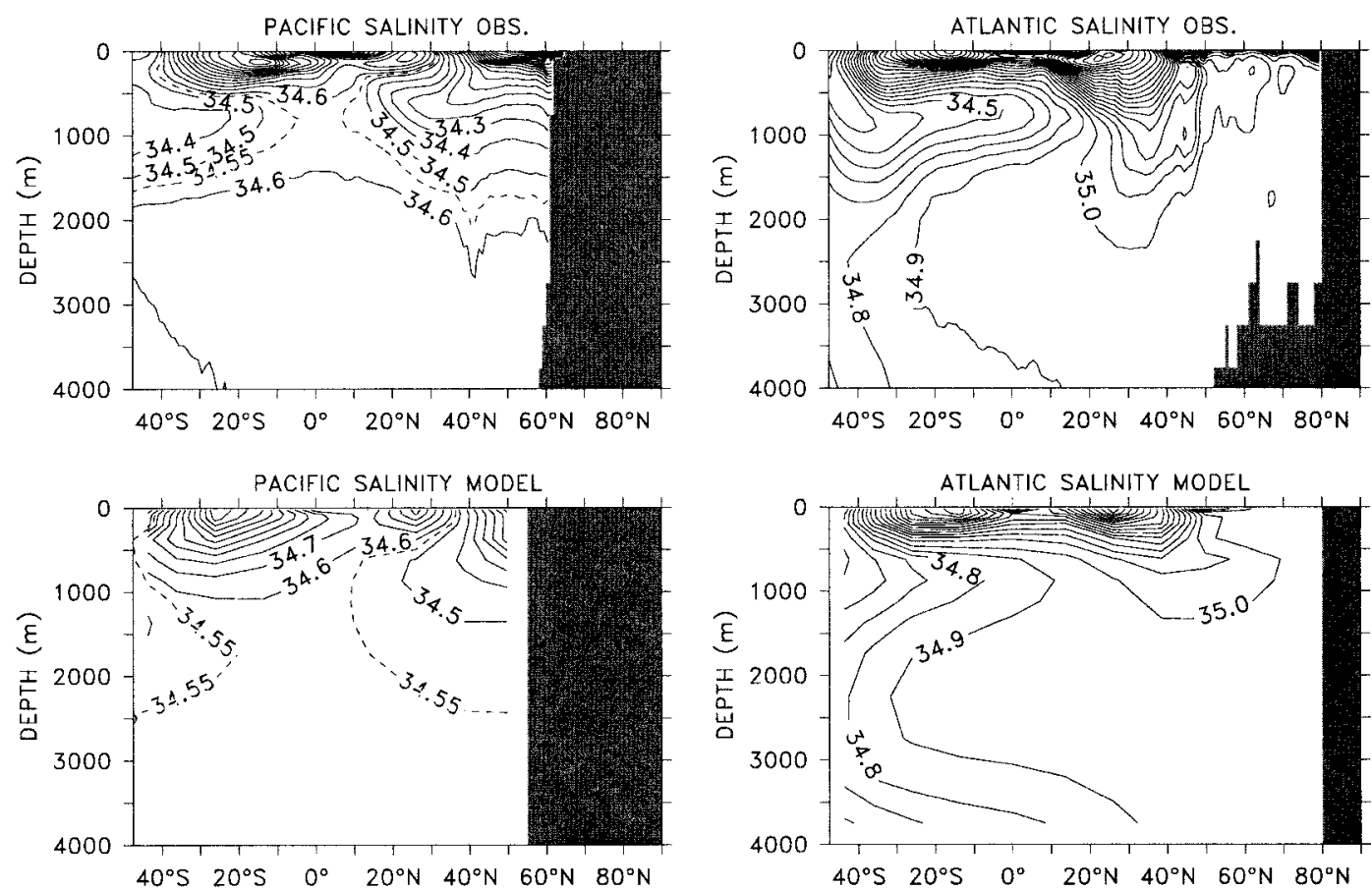

FIG. 13. Latitude-depth sections of simulated (lower panels) annual-mean salinity in the Pacific (left) and Atlantic (right) Oceans. Upper panels show zonally averaged observations from Levitus et al. (1994). Isoline differences are 0.1 with an additional dashed isoline at 34.55 in the left panels.

during the summer months from June to October. Then convection slowly increases the mixed layer depth from November to April. Deep convection appears in late winter/early spring. After April the mixed layer quickly shallows.

\section{Strength and stability of the thermohaline circulation (THC) for seasonal versus annual-mean forcing}

a. Stability of the THC to freshwater perturbations

Here we explore the sensitivity of the North Atlantic thermohaline circulation to seasonal versus annual- mean forcing. Therefore perturbation experiments are conducted in which we add a freshwater anomaly to the northern North Atlantic between $65^{\circ}$ and $80^{\circ} \mathrm{N}$. In a first set of experiments the equilibrium response to a fast perturbation is examined. The freshwater is added permanently in form of a step function with different amplitudes. The overturning of the Atlantic after 1000 years of integration is shown in the left panel of Fig. 17.

For small values of the perturbation the deep water formation decreases linearly with the perturbation amplitude. If the perturbations exceed a certain threshold
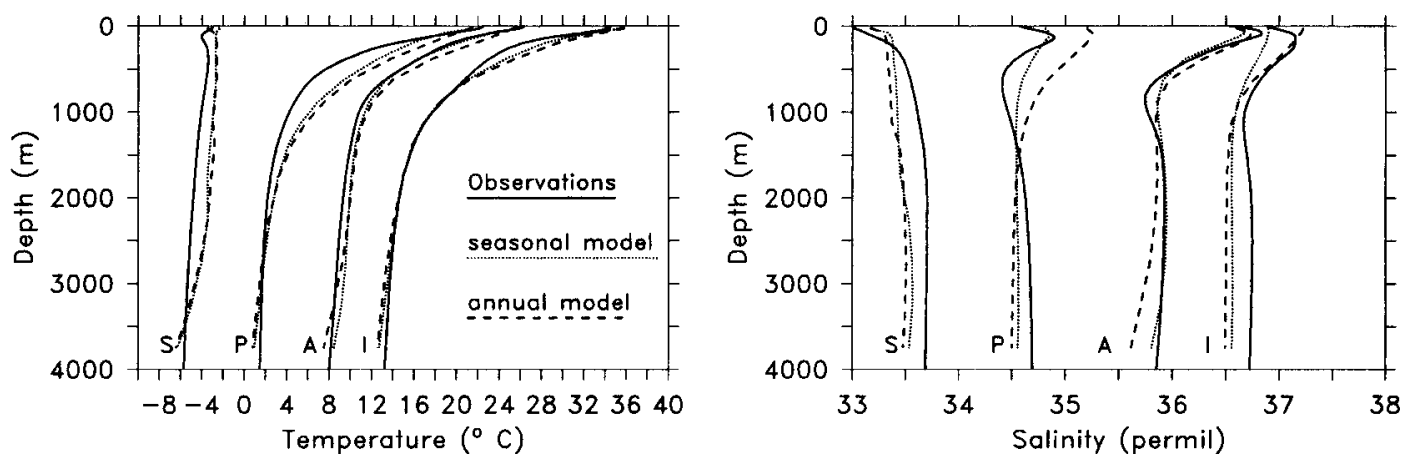

FIG. 14. Zonally and meridionally averaged (left) temperatures and (right) salinities for the four ocean basins as a function of depth. Annual-mean model results from the seasonally forced version, from the annually forced version, and observations (Levitus et al. 1994; Levitus and Boyer 1994) are shown. Results for the Southern Ocean (S) are offset by $-6^{\circ} \mathrm{C}(-1 \mathrm{psu})$, for the Atlantic (A) by $+6^{\circ} \mathrm{C}(+1 \mathrm{psu})$, for the Indic (I) by $+12^{\circ} \mathrm{C}(+2 \mathrm{psu})$, while results for the Pacific (P) are not offset. 

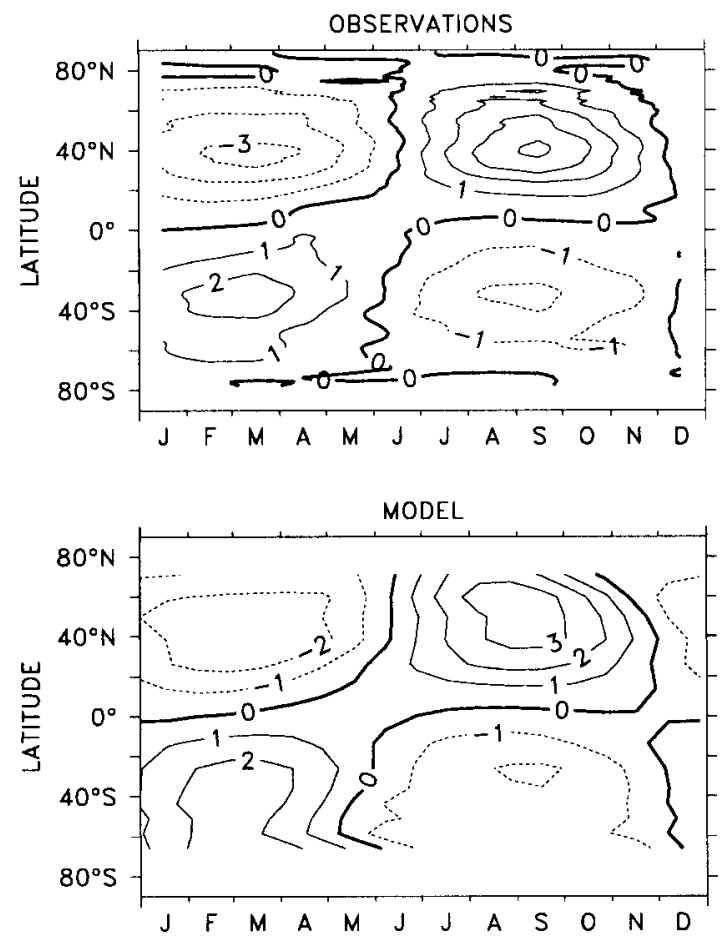

FIG. 15. SST anomalies zonally averaged over all basins as a function of latitude and time. Upper panels show observations (Levitus and Boyer 1994) vertically averaged between the surface and 50-m depth, which corresponds to the depths of the model surface grid boxes. Isoline difference is $1^{\circ} \mathrm{C}$

the system switches into a state without North Atlantic deep water formation. This threshold value is about 0.12 $\mathrm{Sv}$ for the seasonally forced model and $0.08 \mathrm{~Sv}$ for the annual-mean model. If the perturbation is applied slowly (see right panel of Fig. 17) the ocean has more time to mix the freshwater anomalies into the deep layers, and the threshold values increase. However, the difference

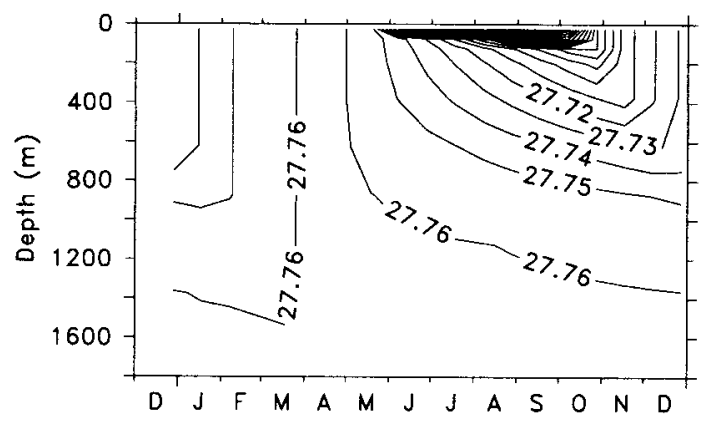

FIG. 16. Potential density $\left(\mathrm{kg} \mathrm{m}^{-3}-1000 \mathrm{~kg} \mathrm{~m}^{-3}\right)$ in the upper $1800 \mathrm{~m}$ of the northern North Atlantic between $65^{\circ}$ and $80^{\circ} \mathrm{N}$ during a seasonal cycle.

between the seasonally forced and the annual-mean model versions are similar as for the fast perturbations.

The new equilibrium state is characterized by a strong reduction of the northward heat flux in the Atlantic. This leads to a cooling of the Northern Hemisphere and a warming of the Southern Hemisphere as shown in Fig. 18. Maximum cooling occurs around $70^{\circ} \mathrm{N}$ in late winter/early spring. The reason is that deep convection and the associated heat loss to the atmosphere occurs during that time in the seasonally forced model (see Fig. 16).

It can also be seen from Fig. 17 that the steady-state overturning of the two model versions is different. The annual-mean version exhibits a deep water formation rate reduced by more than $20 \%$ compared with the seasonally forced model. This can be one reason of the different threshold values. We hypothesize that due to the seasonality of the meridional overturning shown in Fig. 11 the vertical diffusion of heat, particularly at low latitudes, is enhanced in the seasonal model. This leads to a stronger overturning and hence to higher threshold values. If the vertical diffusivity is reduced in the seasonal model until the unperturbed overturning rates are
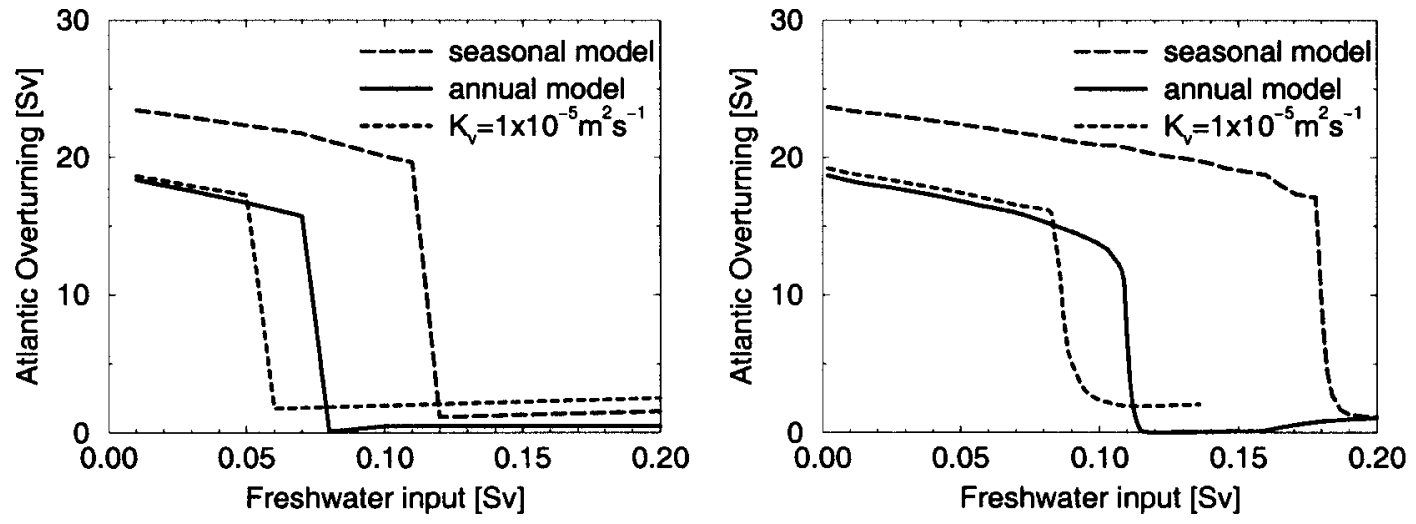

FIG. 17. Maximum streamfunction in the Atlantic as a function of the amount of sustained additional freshwater input in the northernmost box. The left graph shows the equilibrium response to a step function (fast perturbation). In the right graph the freshwater perturbation is slowly increasing by $0.1 \mathrm{~Sv}$ in 1000 years. Three different model versions have been used: a version with full seasonal forcing (dashed), the same version in annual-mean mode (solid), and a seasonally forced version with reduced vertical diffusivity $K_{v}$ (dotted). The standard versions have $K_{v}=4 \times 10^{-5} \mathrm{~m}^{2} \mathrm{~s}^{-1}$. 


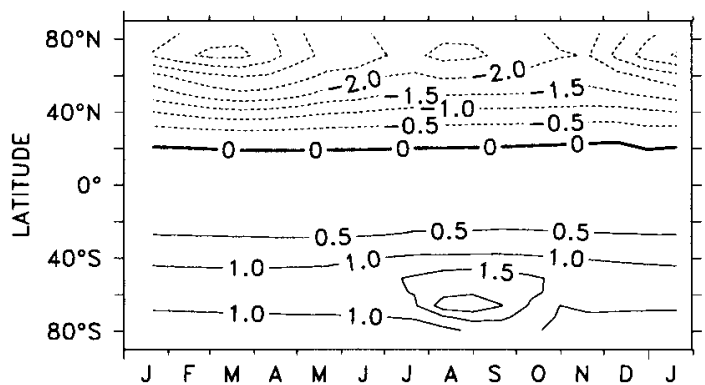

FIG. 18. Near-surface air temperature change $\left({ }^{\circ} \mathrm{C}\right)$ between the equilibrium states with a circulation shutdown and with an active Atlantic thermohaline circulation as a function of latitude and time.

nearly the same for the seasonal and the annual-mean model, the threshold values are much closer as also shown in Fig. 17. This supports our hypothesis that a large part of the difference between the annual-mean forced steady state and the seasonally forced steady state can be explained by an increased effective vertical diffusivity associated with the seasonal variations of the wind-driven circulation.

\section{b. Vertical mixing and the strength of the THC in equilibrium}

In the following we will examine this hypothesis and the differences between the annual-mean and seasonally forced model in further detail. Therefore, we use model versions with identical parameter settings differing only in the applied forcing listed in Table 1. The coupled model is externally forced by three different mechanisms: insolation at the TOA, wind stress at the ocean surface, and near-surface wind velocity in the atmospheric moisture advection. In model version $\mathrm{S}$ all of these parameters are changing with the seasons, while in version A only annual-mean values are used. Note that versions $\mathrm{S}$ and $\mathrm{A}$ are identical with the two model versions used in section 4 referred to as the seasonal and annual-mean model. In order to isolate the importance of the individual terms we additionally use versions with annual-mean values in only one of the forcing terms (AW, AI, AM).

In order to examine vertical diffusion in the deep ocean a passive tracer is injected everywhere at $1750-\mathrm{m}$ depth with a constant rate of $1 \mathrm{yr}^{-1}$. The tracer is then transported through advection, diffusion, and convection. Without any transport the tracer concentration would increase by one every year at the injection level and would be zero elsewhere. In Fig. 19 the tracer concentration averaged over all basins between $30^{\circ} \mathrm{S}$ and $30^{\circ} \mathrm{N}$ is shown at year 100 . The seasonally forced model $\mathrm{S}$ shows lower tracer concentration at the injection level by about $10 \%$ compared with the annual-mean model A. At shallower and deeper levels the tracer concentration is larger in the seasonal model. This shows that vertical diffusion is increased in the seasonally forced
TABLE 1 . Model versions used in the sensitivity experiments. All model parameters are the same; the versions differ only in the applied forcing. In model version AW, for example, seasonal forcing in solar insolation at the top of the atmosphere, annual-mean wind stress at the ocean surface, and seasonally varying near-surface wind velocities in the atmospheric moisture advection term are used. Model version $\mathrm{S} 2$ differs from version $\mathrm{S}$ in that 2 times the seasonal amplitude of the wind stress forcing is used while keeping the annual-mean wind stress constant.

\begin{tabular}{cclc}
\hline \hline $\begin{array}{c}\text { Model } \\
\text { version }\end{array}$ & Insolation TOA & Wind stress & Moisture advection \\
\hline S & seasonal & seasonal & seasonal \\
A & annual mean & annual mean & annual mean \\
AI & annual mean & seasonal & seasonal \\
AW & seasonal & annual mean & seasonal \\
AM & seasonal & seasonal & annual mean \\
S2 & seasonal & $2 \times$ seasonal & seasonal \\
\hline
\end{tabular}

model version. If only the wind stress forcing is held constant throughout the year (AW) but insolation and moisture advection still vary seasonally, the tracer profile is very similar to the annually forced model A. This clearly indicates that the increased vertical diffusion in the seasonally forced model is caused by annually varying wind stress. The wind-induced seasonal overturning shown in Fig. 11 leads to a vertical displacement of water masses at different latitudes. Horizontal diffusion and advection are then acting on these displaced water masses. The combined effect is an increase of vertical mixing throughout the water column.

The effect of seasonality in solar insolation on vertical

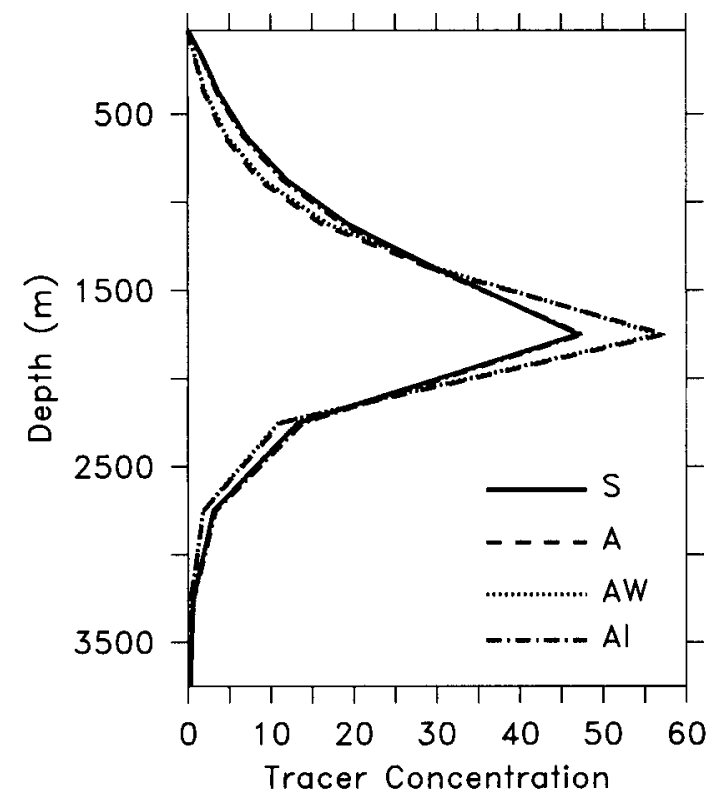

FIG. 19. Vertical profiles of tracer concentration averaged over all basins between $30^{\circ} \mathrm{S}$ and $30^{\circ} \mathrm{N}$ for four model versions listed in Table 1. The tracer has been released at 1750-m depth at all latitudes and in all basins with a rate of $1 \mathrm{yr}^{-1}$. The tracer distribution is shown at year 100. Note that the lines for model versions S and AI on one hand and for A and AW on the other hand are very much overlapping. 


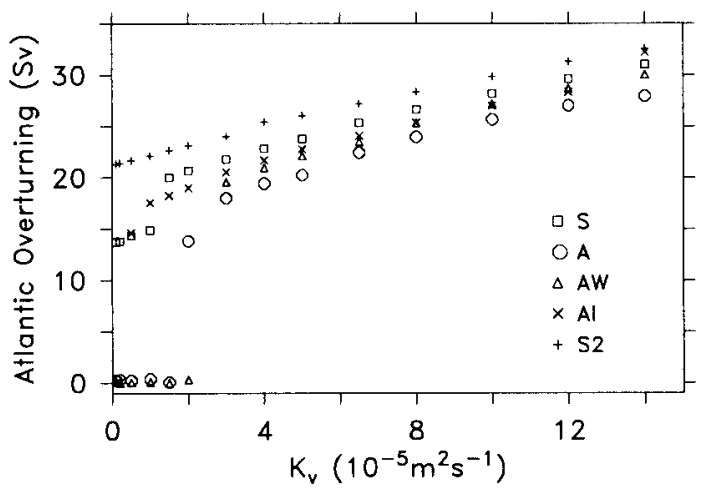

FIG. 20. Maximum of annual-mean North Atlantic overturning below $1000 \mathrm{~m}$ as a function of the explicit vertical eddy diffusivity $K_{v}$ in the ocean for different model versions listed in Table 1.

mixing of water masses in the deep ocean is small as can be seen from the tracer profile of model version AI that is very similar to the seasonally forced model S. The same is true for seasonality in the moisture advection (not shown).

Next we present two attempts to quantify the effect of the seasonal overturning on the effective vertical diffusivity. First we used the model versions described above and changed the vertical eddy diffusivity. After 5000 years of integration a new steady state was reached. In Fig. 20 we show the dependence of the strength of the Atlantic thermohaline circulation on the eddy diffusivity in the new equilibrium. The circulation strength depends monotonically on the eddy diffusivity. Increased downward diffusion of heat leads to a warmer deep ocean, decreased static stability, and increased pressure difference between the deep high and low latitudes. Assuming a power law $\psi \sim\left(K_{v}\right)^{\gamma}$, where $\psi$ is the maximum overturning streamfunction in the Atlantic, we obtain exponents $\gamma=0.33$ for the annual and $\gamma=0.18$ for the seasonal model. The value for the annual-mean model is in good agreement with the values found by Bryan $(1987 ; \gamma=1 / 3)$ using a three-dimensional ocean model and Wright and Stocker (1992; $\gamma=$ 0.36) using the same ocean model as in this study with restoring boundary conditions. The dependence of the streamfunction on the diffusivity is lower if seasonal forcing is applied.

Generally, Atlantic overturning is weaker in the annually forced model (A) than in the seasonally forced version (S) irrespective of the value of $K_{v}$. Version AW (annual mean wind stress) shows slightly larger overturning than version $\mathrm{A}$, while $\mathrm{AI}$ has somewhat smaller overturning than the seasonal model (version $\mathrm{S}$ ). The similarity between versions $\mathrm{S}$ and $\mathrm{AI}$ on the one hand and $\mathrm{A}$ and $\mathrm{AW}$ on the other hand is particularly obvious for small values of $K_{v}$. For versions A, AW, and AI a threshold exists, below which no deep water formation in the North Atlantic is possible. This threshold value is $2 \times 10^{-5} \mathrm{~m}^{2} \mathrm{~s}^{-1}$ for the versions with annual-mean wind stress $\mathrm{A}$ and $\mathrm{AW}$. It is much smaller $\left(0.2 \times 10^{-5}\right.$ $\mathrm{m}^{2} \mathrm{~s}^{-1}$ ) in version AI and in the full seasonally forced model S Atlantic overturning remains active even for values as small as $1 \times 10^{-7} \mathrm{~m}^{2} \mathrm{~s}^{-1}$.

This shows that both, seasonal wind stress forcing as well as seasonal insolation leads to a stronger Atlantic THC compared with annual-mean forcing. The effect of the seasonality in wind stress is larger than that of insolation, particularly for low values of $K_{v}$. Note that these experiments have also been performed for version AM with seasonal wind stress and insolation but annualmean moisture advection. The results are virtually the same as for the seasonal model S, implying that seasonality in the moisture advection, which is largest at low latitudes, has a negligible effect on the strength of the THC in equilibrium. If the amplitude of the seasonal variations in the wind stress is doubled (version S2), while keeping the annual-mean wind stress constant, Atlantic overturning increases for all values of $K_{v}$. This implies that the effect of the seasonal wind stress forcing on effective vertical diffusion and overturning depends on the magnitude of the seasonal variations in wind stress.

From Fig. 20 we can estimate the effect of the seasonal cycle in the meridional circulation on the effective vertical eddy diffusivity as the difference in the diffusivities between the model versions $\mathrm{S}$ and AW. This difference is around $2 \times 10^{-5} \mathrm{~m}^{2} \mathrm{~s}^{-1}$ for the whole range of circulation strengths.

As a second approach of a quantitative estimation of the increased vertical diffusion the vertical penetration of an artificial tracer from the surface is examined for the different model versions. The tracer was set to 1 at the ocean surface and then transported by the model via advection, diffusion, and convection. A penetration depth $\Delta z^{*}$ can be defined as follows:

$$
\Delta z^{*}=\frac{\int C z d z}{\int C d z} .
$$

Here $C$ denotes the tracer concentration and the integration is carried out from the sea surface to the bottom. Since the different model versions show a different mean circulation, with stronger ventilation of the deep ocean in the seasonal model, it is necessary to rule out the effect of the mean circulation on the penetration depth. In order to avoid the influence of the mean circulation on the tracer distribution in the deep ocean, where the tracer is carried mainly through convection at high latitudes and advection and horizontal diffusion at depth, we investigate the penetration depth in the tropical Pacific during the first 20 years after the stepwise tracer supply at year 0 . At year 20 the tracer concentration in the deep tropical Pacific is still negligible. An effective vertical diffusivity $K_{v}^{*}$ can be defined by 


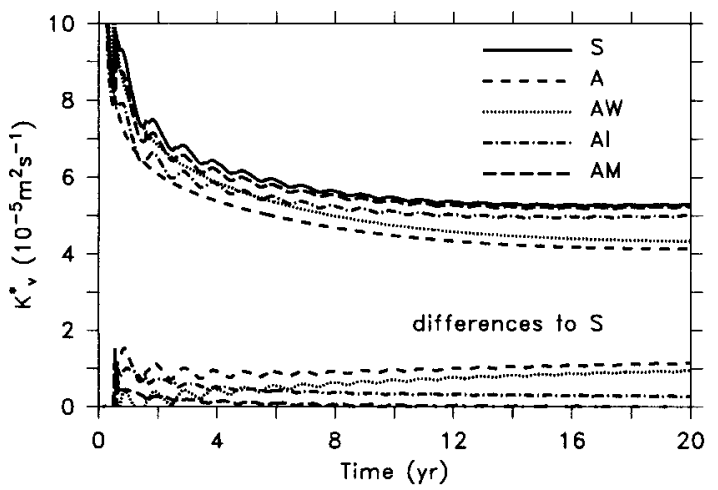

FIG. 21. Effective vertical diffusivities in the tropical $\left(20^{\circ} \mathrm{S}-20^{\circ} \mathrm{N}\right)$ Pacific as a function of time. Values are calculated from the penetration depth of a tracer released at the sea surface at time 0 .

$$
K_{v}^{*}=\frac{\left(\Delta z^{*}\right)^{2}}{\Delta t},
$$

where $\Delta t$ is the time elapsed since the beginning of the experiment. In Fig. 21 the effective diffusivities in the tropical Pacific are plotted as a function of time for the different model versions. Around year 20 the values approach a minimum. After year 20 the effective diffusivities slowly increase again as the tracer concentration in the deep ocean increases (not shown). For the annual-mean model the effective diffusivity $K_{v}^{*}$ around year 20 approaches the explicit diffusivity $K_{v}=4 \times$ $10^{-5} \mathrm{~m}^{2} \mathrm{~s}^{-1}$. In the seasonal model the effective diffusivity approaches a larger value. The difference between the seasonal and annual effective diffusivities is about $1 \times 10^{-5} \mathrm{~m}^{2} \mathrm{~s}^{-1}$ and this value is reached very fast after the beginning of the experiment. The results from model versions AW, AI, and AM confirm the relative importance of the different forcing mechanisms to the differences in the seasonal and annual models already described above. Seasonal windstress forcing is the largest influence on vertical mixing and overturning strength, followed by seasonal insolation, whereas seasonality in moisture advection plays a negligible role. While in the previous experiments, in which the tracer was injected at 1750-m depth, the differences between the annual-mean and seasonal model versions could be almost entirely explained by the wind stress effect (see Fig. 19), here the effect of the seasonality in insolation seems to have a larger influence. This is most probably due to the effect of the seasonally varying thermocline on the vertical tracer transport in surface and subsurface waters.

Summing up, the effect of the seasonally varying meridional overturning on the effective vertical eddy diffusivity is estimated to be between $1 \times 10^{-5} \mathrm{~m}^{2} \mathrm{~s}^{-1}$ and $2 \times 10^{-5} \mathrm{~m}^{2} \mathrm{~s}^{-1}$ in this model. The values would be larger for an increased seasonal amplitude of the wind stress forcing.

\section{Conclusions}

We have shown that the coupling strategy used for the annual-mean model (Stocker et al. 1992) can also be applied for the seasonally forced version with some minor changes. Therefore, atmospheric parameters are calculated such that the heat and freshwater fluxes of the atmosphere match those from the ocean spinup. The use of annual-mean values from the ocean spinup and from observations for the determination of the atmospheric parameters enables an independent validation of the simulated seasonal cycle. After coupling, the system settles into a state similar to the one prior to coupling without the use of explicit flux corrections. The performance of the annual variations on the largest spatial scales is quite satisfactory. Largest errors appear in the parameterizations of the hydrological cycle particularly of evaporation and precipitation. At the top of the atmosphere the largest errors (up to 15\%) occur in the parameterization of outgoing longwave radiation in the Tropics. It is likely that these errors are reflected in the surface energy balance and in the simulation of surface air temperatures and SSTs. However, their influence is not very large and the simulated seasonal cycle in both SSTs and surface air temperatures is in good agreement with observations. The simulation of the deep ocean water masses is also in reasonable agreement with observations. Deep water properties are similar in the seasonally forced model and in the annual-mean model. This suggests that the large-scale circulation and water mass properties of the deep ocean are largely determined by the annual-mean heat and freshwater fluxes and are relatively insensitive to errors in their seasonal variation.

Both the seasonal as well as the annual model exhibit two stable equilibrium states. One corresponds to today's thermohaline circulation with deep water formation in the North Atlantic and the other to a state with absent North Atlantic deep water production. Therefore, the fundamental solution structure of the coupled model is not dependent on the seasonal cycle. This is consistent with three-dimensional coupled atmosphere-ocean model results (Manabe and Stouffer 1999). The different sensitivity of the thermohaline circulation for a transition between these states concerning seasonal or annualmean forcing is due to a stronger equilibrium overturning in the seasonally forced model. Both, seasonal wind stress forcing and seasonal variations in insolation at the top-of-atmosphere contribute to the enhanced overturning. However, the effect of the seasonality in the wind stress forcing is larger than that for insolation. Seasonally varying wind stress induces seasonal changes in the meridional overturning that increases vertical mixing of water properties. This increased effective vertical diffusivity has been estimated to be $1 \times 10^{-5}$ to $2 \times 10^{-5} \mathrm{~m}^{2} \mathrm{~s}^{-1}$. Currently used values of the vertical diffusivity in coarse-resolution ocean general circulation models are often larger than those inferred from observations (Manabe and Stouffer 1999; Ledwell et al. 
1994). Our results suggest that in a seasonally forced model much smaller values of the vertical eddy diffusivity might be chosen than in a model with annualmean forcing, without leading to an unrealistic THC. Because vertical diffusion, or more generally mixing, is a key process in determining overturning, water mass composition, and stability thresholds, the seasonal cycle is an important extension of this climate model for future experiments.

Acknowledgments. We thank two anonymous reviewers for their comments and suggestions. ERBE data have been provided from the National Center of Atmospheric Research (NCAR) Climate Analysis Section (CAS) Data Catalog online at Web site: http://www.cgd.ucar. edu/cas/catalog/satellite/erbe/means 2 . html. Reanalyses data have been used from the NOAA Climate Diagnostics Center (Web site at http://www.cdc.noaa.gov/) and from the European Centre for Medium-Range Weather Forecasts. This study was supported by the Swiss National Science Foundation and by NSERC Strategic Grant STP0192999.

\section{REFERENCES}

Baumgartner, A., and E. Reichel, 1975: The World Water Balance. Elsevier, $179 \mathrm{pp}$.

Berger, A., 1988: Milankovic theory and climate. Rev. Geophys., 26, 624-658.

_- M.-F. Loutre, and C. Tricot, 1993: Insolation and Earth's orbital periods. J. Geophys. Res., 98, 10 341-10 362.

— - - - and H. Gallée, 1998: Sensitivity of the LLN climate model to the astronomical and $\mathrm{CO}_{2}$ forcings over the last 200 ky. Climate Dyn., 14, 615-629.

Bond, G., W. S. Broecker, S. J. Johnsen, J. McManus, L. Labeyrie, J. Jouzel, and G. Bonani, 1993: Correlations between climate records from North Atlantic sediments and Greenland ice. $\mathrm{Na}$ ture, 365, 143-147.

Broecker, W. S., 1997: Thermohaline circulation, the Achilles heel of our climate system: Will man-made $\mathrm{CO}_{2}$ upset the current balance? Science, 278, 1582-1588.

Bryan, K., 1987: Parameter sensitivity of primitive equation ocean general circulation models. J. Phys. Oceanogr., 17, 970-985.

- and L. J. Lewis, 1979: A water mass model of the world oceans. J. Geophys. Res., 84, 2503-2517.

Dansgaard, W., and Coauthors, 1993: Evidence for general instability of past climate from a 250-kyr ice-core record. Nature, 364, 218-220.

ERBE, 1990: Earth radiation budget experiment. Eos, Trans. Amer. Geophys. Union, 71, 297-305.
Gibson, R., P. Kållberg, S. Uppala, A. Nomura, A. Hernandez, and E. Serrano, 1997: ERA description. ECMWF Re-Analysis Project Report Series, Vol. 1, ECMWF, Reading, United Kingdom.

Imbrie, J., and Coauthors, 1992: On the structure and origin of major glaciation cycles. 1. Linear responses to Milankovitch forcing. Paleoceanography, 7, 701-738.

Kalnay, E., and Coauthors, 1996: The NCEP/NCAR 40-Year Reanalysis Project. Bull. Amer. Meteor. Soc., 77, 437-471.

Ledwell, J. R., A. J. Watson, and C. S. Law, 1994: Evidence for slow mixing across the pycnocline from an open-ocean tracer release experiment. Nature, 364, 701-703.

Levitus, S., and T. P. Boyer, 1994: Temperature. Vol. 4, World Ocean Atlas 1994, NOAA Atlas NESDIS 4, 117 pp.

_, R. Burgett, and T. P. Boyer, 1994: Salinity. Vol. 3, World Ocean Atlas 1994, NOAA Atlas NESDIS 3, 99 pp.

Maier-Reimer, E., U. Mikolajewicz, and K. Hasselmann, 1993: Mean circulation of the Hamburg LSG OGCM and its sensitivity to the thermohaline surface forcing. J. Phys. Oceanogr., 23, 731757.

Manabe, S., and R. J. Stouffer, 1999: Are two modes of thermohaline circulation stable? Tellus, 51A, 400-411.

Nakano, H., R. Furue, and N. Suginohara, 1999: Effect of seasonal forcing on global circulation in a world ocean circulation model. Climate Dyn., 15, 491-502.

North, G. R., J. G. Mengel, and D. A. Short, 1983: Simple energy balance model resolving the seasons and the continents: Application to the astronomical theory of Ice Ages. J. Geophys. Res., 88 (C11), 6576-6586.

Paillard, D., and L. Labeyrie, 1994: Role of the thermohaline circulation in the abrupt warming after Heinrich events. Nature, 372, 162-164.

Peixoto, J. P., and A. H. Oort, 1992: Physics of Climate. American Institute of Physics, $520 \mathrm{pp}$.

Sausen, R., K. Barthel, and K. Hasselmann, 1988: Coupled oceanatmosphere models with flux correction. Climate Dyn., 2, 145163.

Schmittner, A., and T. F. Stocker, 1999: The stability of the thermohaline circulation in global warming experiments. J. Climate, 12, 1117-1133.

— C. Appenzeller, and T. F. Stocker, 2000: Validation of parameterisations for the meridional energy and moisture transport used in simple climate models. Climate Dyn., 16, 63-77.

Schmitz, W. J., 1995: On the interbasin-scale thermohaline circulation. Rev. Geophys., 33, 151-173.

Stocker, T. F., and D. G. Wright, 1996: Rapid changes in ocean circulation and atmospheric radiocarbon. Paleoceanography, 11, 773-796.

—,- , and L. A. Mysak, 1992: A zonally averaged, coupled ocean-atmosphere model for paleoclimate studies. J. Climate, 5, 773-797.

Trenberth, K. E., 1997: Using atmospheric budgets as a constraint on surface fluxes. J. Climate, 10, 2796-2809.

Wright, D. G., and T. F. Stocker, 1992: Sensitivities of a zonally averaged global ocean circulation model. J. Geophys. Res., 97, $12707-12730$ 